\title{
Gaucher Disease and Cancer: Concept and Controversy
}

\author{
Francis Y. M. Choy ${ }^{1}$ and Tessa N. Campbell ${ }^{2}$ \\ ${ }^{1}$ Department of Biology, Centre for Biomedical Research, University of Victoria, P.O. Box 3020, Station CSC, \\ Victoria, BC, Canada V8W 3N5 \\ ${ }^{2}$ TNC Scientific Consulting, Calgary, AB, Canada \\ Correspondence should be addressed to Francis Y. M. Choy, fchoy@uvic.ca
}

Received 27 January 2011; Revised 2 April 2011; Accepted 15 April 2011

Academic Editor: Anton M. Jetten

Copyright ( $) 2011$ F. Y. M. Choy and T. N. Campbell. This is an open access article distributed under the Creative Commons Attribution License, which permits unrestricted use, distribution, and reproduction in any medium, provided the original work is properly cited.

Gaucher disease is an inherited disorder caused by a deficiency in the lysosomal hydrolase glucocerebrosidase. There is a wide spectrum of clinical presentations, with the most common features being hepatosplenomegaly, skeletal disease, and cytopenia. Gaucher disease has been classified into three broad phenotypes based upon the presence or absence of neurological involvement: Type 1 (nonneuronopathic), Type 2 (acute neuronopathic), and Type 3 (subacute neuronopathic). The two main treatment options include enzyme replacement therapy and substrate reduction therapy. Recently, discussion has escalated around the association of Gaucher disease and cancer, with conflicting reports as to whether Gaucher patients have an increased risk of malignancy. In this review, we present both the concept and controversy surrounding the association of Gaucher disease with cancer.

\section{Introduction}

Gaucher disease is a panethnic autosomal recessive disorder characterized by a heterogeneous set of signs and symptoms caused by the defective hydrolysis of glucocerebroside. A deficiency in the enzyme glucocerebrosidase (glucosylceramidase, acid $\beta$-glucosidase) leads to the accumulation of glucocerebroside in the spleen, liver, and bone marrow. The resultant hepatosplenomegaly, haematological changes, and orthopaedic complications are the predominant symptoms [1]. Gaucher disease has been classified into three broad phenotypes. Type 1, the most common form, has no central nervous system involvement. Conversely, patients with Type 2 (acute neuronopathic disease) suffer from an aggressive form that leads to death perinatally or within the first few years of life. In Type 3 (subacute neuronopathic disease), patients show neurodegenerative symptoms but are able to survive through childhood to adulthood $[2,3]$.

The glucocerebrosidase gene is found on chromosome 1q21-22, consisting of 11 exons encoding a 497-aminoacid protein. A highly homologous pseudogene, located $16 \mathrm{~kb}$ downstream, complicates mutation analysis in this region. To date, nearly 300 mutations have been identified in Gaucher's patients, including point mutations, deletions, insertions, splice site mutations, frame-shift mutations, and recombinant alleles [4-6].

Gaucher disease is the most common lysosomal storage disorder and the first to be successfully treated by enzyme replacement therapy [7]. In 1991, alglucerase (Ceredase, Genzyme Inc.), the placental derivative of glucocerebrosidase was FDA-approved. In 1994, the human recombinantform imiglucerase (Cerezyme, Genzyme Inc.) received FDA approval. Alglucerase is only available today for a handful of patients who are unable to tolerate imiglucerase [8]. In 2010, the FDA-approved velaglucerase alfa (VPRIV), a human fibroblast-derived glucocerebrosidase developed by Shire, Cambridge, Mass, USA for treatment of Gaucher disease $[9,10]$. Taliglucerase alfa (UPLYSO), a recombinant glucocerebrosidase derived from plant cells developed by Protalix BioTherapeutics, Karmiel, Israel, is presently under FDA review [11].

Currently, the extreme expense of enzyme replacement therapy has led to a widespread search for more efficient and cost-effective methods of protein production and alternate therapies, resulting in a closer examination of glucocerebrosidase biosynthesis and current therapeutic techniques $[12,13]$. Substrate reduction/inhibition therapy (miglustat, Zavesca, Actelion Pharmaceuticals) was approved by the 
TABLE 1: Examples of reported associations of Gaucher disease with multiple myeloma. * Note: the number in the bracket represents the reference number in the current Choy and Campbell publication.

\begin{tabular}{|c|c|c|}
\hline Date & Title & Authors \\
\hline 1965 & Coincidence of multiple myeloma with Gaucher disease & Pinkhas et al. [15]* \\
\hline 1968 & Immunoglobulin anomalies in Gaucher disease: Report of 16 cases & Pratt et al. [16] \\
\hline 1979 & Nonsecretory IgD-kappa multiple myeloma in a patient with Gaucher disease & $\begin{array}{l}\text { Benjamin et al. } \\
{[17]}\end{array}$ \\
\hline 1980 & Coexistence of IgA myeloma and Gaucher disease & Ruestow et al. [18] \\
\hline 1982 & Coexistence of Gaucher disease and multiple myeloma & Garfinkel et al. [19] \\
\hline 1988 & Sequential appearance of breast carcinoma, multiple myeloma, and Gaucher disease & Gal et al. [20] \\
\hline 1991 & $\begin{array}{l}\text { Case report: serendipitous Gaucher disease presenting as elevated erythrocyte } \\
\text { sedimentation rate due to monoclonal gammopathy }\end{array}$ & Liel et al. [21] \\
\hline 1993 & Increased risk of cancer in patients with Gaucher disease & Shiran et al. [22] \\
\hline 1995 & Complex IgA gammopathy in Gaucher disease & Shvidel et al. [23] \\
\hline 1997 & $\begin{array}{l}\text { Multiple myeloma arising from monoclonal gammopathy of undetermined } \\
\text { significance in a patient with Gaucher disease }\end{array}$ & Brady et al. [24] \\
\hline 2000 & $\begin{array}{l}\text { Coincidence of Gaucher disease due to a } 1226 \mathrm{G} / 1448 \mathrm{C} \text { mutation and of an } \\
\text { immunoglobulin G lambda multiple myeloma with Bence-Jones proteinuria }\end{array}$ & Harder et al. [25] \\
\hline 2000 & Uncommon combination of multiple myeloma in three patients & Mateja et al. [26] \\
\hline 2005 & Gaucher disease and cancer incidence: a study from the Gaucher's Registry & $\begin{array}{l}\text { Rosenbloom et al. } \\
{[27]}\end{array}$ \\
\hline 2006 & Increased incidence of cancer in adult Gaucher disease in Western Europe & De Fost et al. [28] \\
\hline 2009 & $\begin{array}{l}\text { The underrecognized progressive nature of N370S Gaucher disease and assessment } \\
\text { of cancer risk in } 403 \text { patients }\end{array}$ & Taddei et al. [29] \\
\hline 2010 & $\begin{array}{l}\text { Expanding the spectrum of the association between Type } 1 \text { Gaucher disease and } \\
\text { cancers: a series of patients with up to } 3 \text { sequential cancers of multiple } \\
\text { types-correlation with genotype and phenotype }\end{array}$ & Lo et al. [30] \\
\hline
\end{tabular}

EMA (2002) and FDA (2003) for adult patients unsuitable for enzyme replacement therapy. Eliglustat tartrate, a newer substrate reduction agent manufactured by Genzyme Inc., was reported to cause fewer side effects upon completion of a phase II clinical trial [14]. Other treatment avenues being explored are chaperone therapy, whereby the mutant lysosomal protein is stabilized for delivery to the lysosome, and gene therapy, which introduces the normal glucocerebrosidase gene into the cells of an affected individual [13].

This heightened search for more efficient and costeffective treatments has led to greater scrutiny of the heterogeneity of Gaucher disease clinical presentation. One result has been the recent escalation of discussion regarding the possible correlation between Gaucher disease and cancer, with conflicting reports as to whether Gaucher's patients have an increased risk of malignancy. In this review, we present both the concept and the controversy concerning the association of Gaucher disease and cancer.

\section{Gaucher Disease and Cancer: Concept}

Numerous studies have reported an increased risk of cancer in Gaucher disease patients. Associated cancers include multiple myeloma (Table 1, [15-30]), chronic lymphocytic leukemia [31-34], chronic myeloid leukemia [35, 36], acute leukemia [37-39], large B-cell lymphoma [40], T-cell lymphoma [41], Hodgkin's disease [42-44], glioblastoma multiforme [45], lung cancer [46, 47], dysgerminoma [48], hepatocellular carcinoma $[49,50]$, and bone cancer [51-54]. Of the aforementioned malignancies, multiple myeloma has been most frequently reported (Table 1 ). The majority of the documented correlations have been with Type 1 (nonneuronopathic) Gaucher disease, with a cited cooccurrence of myeloma 6-50 times more often than expected [27, 28]. A recent study by Taddei et al. [29] delved further into this association by concentrating on individuals with the N370S mutation, the most common mutation in Type 1 Gaucher's patients. There was a conspicuous increase in lifetime risk of multiple myeloma in the entire cohort (RR 25), mostly confined to N370S homozygous patients. The risk of other hematologic malignancies (RR 3.45) and overall cancer risk (RR 1.80) was elevated.

Several theories have been suggested to explain an association between Gaucher disease and cancer. One set of hypotheses focuses on the accumulation of glucocerebroside as the main culprit by impacting immune system regulation in a number of different ways. Costello et al. [55] postulated that exaggerated B-cell function may be 
secondary to stimulation by accumulated glucocerebroside, T-cell function dysregulation, augmented macrophage activation, and disruption of antigen presentation. Moreover, it has been suggested that progressive accumulation of glucocerebroside may trigger macrophage activation, leading to chronic stimulation of the immune system [56]. This could result in enhanced cytokine secretion and subsequent clonal B-cell expansion, setting the stage for eventual transformation [57]. In support of this, elevated levels of specific cytokines, including IL-1, IL-6, IL-8, IL-10, and TNF- $\alpha$, have been found in Gaucher's patients [58-63]. Normal mesenchymal stem cells treated with conduritol Bepoxide, a potent inhibitor of glucocerebrosidase, showed an upregulation of an array of inflammatory mediators, including CCL2, and other differentially regulatory pathways [63]. Primary amyloidosis, a well-recognized consequence of hypergammaglobulinemia, has also been reported in Gaucher disease [64-66]. In another theory, immune system dysregulation resulting from glucocerebroside accumulation may also impact malignant development through reduced immune surveillance due to CD1d-mediated imbalances in regulatory and natural killer (NK) $\mathrm{T}$ cells $[30,67,68]$. The CD1d complex, through which NK T cells recognize glycolipids, has been reported to be elevated in Gaucher's patients and in control monocytes treated with a glucocerebrosidase inhibitor [69]. A resulting T-cell dysfunction may therefore prevent immunoregulation, allowing neoplastic cells to emerge $[30,56,67]$. Mistry et al. [70] reported that in the glucocerebrosidase gene-deficient mouse, there is widespread dysfunction of not only macrophages, but also thymic T cells, dendritic cells, and osteoblasts.

Accumulated substrate is not the only player suggested in the proposed association of Gaucher disease and cancer. Attention has been directed towards the mutant glucocerebrosidase molecules themselves that fail to traffic to the lysosome due to posttranslational misfolding [71]. Retention in the endoplasmic reticulum may lead to the formation of potentially harmful protein aggregates, causing cellular toxicity by endoplasmic reticulum stress and proteosomal overload. Subsequent effects on cell signalling, survival and antigen presentation could impact on all aspects of Gaucher's pathology, adding a further level of complexity to the heterogeneity of the disease [57]. In theory, such a mechanism could operate in clinically unaffected carriers who possess a single missense mutation. Interestingly, a disproportionately large number of heterozygous Gaucher's mutations have been reported in patients with Parkinsonian syndromes [72].

\section{Gaucher Disease and Cancer: Controversy}

The concept of the correlation of Gaucher disease with an elevated incidence of malignancy has remained controversial, mainly due to the infrequency of the association. Though cooccurrence of some cancers, particularly myeloma, has been reported to be increased compared to the general population, malignancies are still uncommon events in the Gaucher's patient population as a whole [73]. Moreover, a number of studies have either reported no higher overall risk of cancer, at least during early or middle age, or in agematched populations [27, 74]. Landgren et al. [75] reported that there was no specific increased risk for myeloma in Gaucher's patients, although the validity of their findings was challenged by Weinreb et al. [76] who noted that the entire cohort of patients in the Landgren study was identified as having Gaucher disease using the International Classification of Diseases 8th Revision code that includes other lysosomal storage diseases such as Fabry's disease, thus complicating the interpretation of the data. Recently, Rosenbloom et al. [77] took a reverse approach by examining multiple myeloma patients for the presence of glucocerebrosidase mutations. The 95 patients, ranging in age from 43-92 years, had bone marrow confirmation of the diagnosis of multiple myeloma. Only two patients carried a glucocerebrosidase mutation, both being heterozygous for the N370S mutation most commonly seen in Type 1 Gaucher disease. Therefore, in this study, there was no apparent relationship between heterozygosity for a Gaucher's mutation and the presence of multiple myeloma [77]. Overall, because the risk of cancer is ill-defined for Gaucher's patients, many physicians are reticent to alarm patients with regard to a potential malignancy risk in addition to their metabolic condition [57].

Another area of controversy involves the explanation of why a certain small subset of Gaucher's patients might develop cancer. One suggestion by Zimran et al. [78] was that the enzyme replacement therapy used to treat patients may contribute to a transformative environment by decreasing the levels of glucocerebroside and its potential accompanying anti-inflammatory and beneficial immunomodulatory effects. The authors postulate that oversuppression of the native circulatory levels of glucocerebroside by enzyme replacement therapy may disrupt the balance and induce the untoward cascade of comorbidities that are not seen in patients exposed to less exogenous enzyme. Therefore, it was suggested that, for Gaucher's patients with very mild features, enzyme replacement therapy, especially at high doses, may not be justified as the risk may be greater than the benefit. Not surprisingly, the implication of enzyme replacement therapy as a potential agent in the development of malignancy has ignited heated responses [30, 73], heightening the already controversial nature of the possible connection between Gaucher disease and cancer.

\section{Perspectives}

The extent of the association between Gaucher disease and cancer remains unclear, resulting in a climate of controversy. Adding to this complexity is emerging data on relationships between Gaucher disease and other comorbidities, such as autoimmune disease, osteoporosis, and Parkinson's disease $[72,79,80]$. The investigation of the underlying fundamental mechanisms behind such relationships warrants more study. A diverse array of available approaches, ranging from gene expression analysis to stem cell and animal models, makes such investigations a reality [81-85]. Moreover, greater sharing of information through specialized databases such as the International Collaborative Gaucher's Group Registry 
may serve to both clarify relationships and provide additional therapeutic targets and goals for Gaucher disease [86]. It should be noted that while the association of Gaucher disease with cancer needs further clarification, Gaucher's patients should, like normal control populations, be encouraged to participate in cancer prevention programs.

\section{Abbreviations}

NK: Natural killer

EMA: European Medicines Agency

FDA: US Food and Drug Administration

RR: $\quad$ Relative risk

IL: Interleukin

TNF- $\alpha$ : Tumour necrosis factor-alpha

N370S: Substitution of serine for asparagine at amino acid 370 .

\section{Acknowledgments}

This work was supported by Natural Sciences and Engineering Research Council Discovery Grant no. 138216-2009 to FYMC. T. N. Campbell of TNC Scientific Consulting received no financial remuneration. No conflict of interests is present.

\section{References}

[1] O. Harmanci and Y. Bayraktar, "Gaucher disease: new developments in treatment and etiology," World Journal of Gastroenterology, vol. 14, no. 25, pp. 3968-3973, 2008.

[2] E. Beutler and G. A. Grabowski, "Gaucher disease," in The Metabolic and Molecular Bases of Inherited Disease, C. R. Scriver, A. L. Beaudet, and W. S. Sly, Eds., pp. 3635-3668, McGraw-Hill, New York, NY, USA, 2001.

[3] M. Fuller, "Sphingolipids: the nexus between Gaucher disease and insulin resistance," Lipids in Health and Disease, vol. 9, p. $113,2010$.

[4] J. R. Wafaei and F. Y. Choy, "Glucocerebrosidase recombinant allele: molecular evolution of the glucocerebrosidase gene and pseudogene in primates," Blood Cells, Molecules, and Diseases, vol. 35, no. 2, pp. 277-285, 2005.

[5] F. Y. Choy, W. Zhang, H. P. Shi et al., "Gaucher disease among Chinese patients: review on genotype/phenotype correlation from 29 patients and identification of novel and rare alleles," Blood Cells, Molecules, and Diseases, vol. 38, no. 3, pp. 287-293, 2007.

[6] K. S. Hruska, M. E. LaMarca, C. R. Scott, and E. Sidransky, "Gaucher disease: mutation and polymorphism spectrum in the glucocerebrosidase gene (GBA)," Human Mutation, vol. 29, no. 5, pp. 567-583, 2008.

[7] M. de Fost, J. M. Aerts, and C. E. Hollak, "Gaucher disease: from fundamental research to effective therapeutic interventions," Netherlands Journal of Medicine, vol. 61, no. 1, pp. 3-8, 2003.

[8] D. Elstein and A. Zimran, "Review of the safety and efficacy of imiglucerase treatment of Gaucher disease," Journal of Biologics, vol. 3, pp. 407-417, 2009.

[9] J. M. F. G. Aerts, M. Yasothan, and P. Kirkpatrick, "Velglucerase alfa," Nature Reviews Drug Discovery, vol. 9, no. 1, pp. 837-838, 2010.

[10] A. Zimran, G. Altarescu, M. Phillips et al., "Phase 1/II ansd extension study of velaglucerse alfa (Gene-Activated Human
Glucocerebrosidase) replacement therapy in adults with type 1 Gaucher disease: 48 months experience," Blood, vol. 115, pp. 4651-4656, 2010.

[11] D. Aviezer, E. Almen-Brill, Y. Shaaltiel, R. Chertkoff, S. Hashmueli, and A. Zimran, "Novel enzyme replacement therapy for Gaucher disease: Phase III pivotal clinical trial with plant cell expressed recombinant glucocerebrosidase (prGCD)-taliglucerase alfa," in Proceedings of the 6th Annual WORLD Symposium, Miami, Fla, USA, 2010.

[12] T. N. Campbell and F. Y. M. Choy, "Knockdown of chimeric glucocerebrosidase by green fluorescent protein-directed small interfering RNA," Genetics and Molecular Research, vol. 3, no. 2, pp. 282-287, 2004.

[13] T. M. Cox, "Gaucher disease: clinical profile and therapeutic developments," Journal of Biologics, vol. 4, pp. 299-313, 2010.

[14] E. Lukina, N. Watman, E. A. Arreguin et al., "Improvement in hematological, visceral, and skeletal manifestations of Gaucher disease type 1 with oral eliglustat tartrate (Genz112638) treatment: 2 -year results of a phase 2 study," Blood, vol. 116, pp. 4095-4098, 2010.

[15] J. Pinkhas, M. Djaldetti, and M. Yaron, "Coincidence of multiple myeloma with Gaucher's disease," Israel Journal of Medical Sciences, vol. 1, no. 4, pp. 537-540, 1965.

[16] P. W. Pratt, S. Kochwa, and S. Estren, "Immunoglobulin abnormalities in Gaucher's disease. Report of 16 cases," Blood, vol. 31, no. 5, pp. 633-640, 1968.

[17] D. Benjamin, H. Joshua, M. Djaldetti, B. Hazaz, and J. Pinkhas, "Nonsecretory IgD-kappa multiple myeloma in a patient with Gaucher's disease," Scandinavian Journal of Haematology, vol. 22, no. 2, pp. 179-184, 1979.

[18] P. C. Ruestow, D. J. Levinson, R. Catchatourian, S. Sreekanth, H. Cohen, and S. Rosenfeld, "Coexistence of IgA myeloma and Gaucher's disease," Archives of Internal Medicine, vol. 140, pp. 1115-1116, 1980.

[19] D. Garfinkel, Y. Sidi, M. Ben-Bassat, F. Salomonm, B. Hazaz, and J. Pinkhaus, "Coexistence of Gaucher's disease and multiple myeloma," Archives of Internal Medicine, vol. 142, pp. 2229-2230, 1982.

[20] R. Gal, S. Gukovsky-Oren, S. Floru, M. Djaldetti, and E. Kessler, "Sequential appearance of breast carcinoma, multiple myeloma and Gaucher's disease," Haematologica, vol. 73, no. 1, pp. 63-65, 1988.

[21] Y. Liel, M. J. Hausmann, and M. Mozes, "Case report: serendipitous Gaucher's disease presenting as elevated erythrocyte sedimentation rate due to monoclonal gammopathy," American Journal of the Medical Sciences, vol. 301, no. 6, pp. 393-394, 1991.

[22] A. Shiran, B. Brenner, A. Laor, and I. Tatarsky, "Increased risk of cancer in patients with Gaucher disease," Cancer, vol. 72, no. 1, pp. 219-224, 1993.

[23] L. Shvidel, N. Hurwitz, M. Shtalrid, S. Zur, O. Oliver, and A. Berrebi, "Complex IgA gammopathy in Gaucher's disease," Leukemia and Lymphoma, vol. 20, no. 1-2, pp. 165-168, 1995.

[24] K. Brady, L. Corash, and V. Bhargava, "Multiple myeloma arising from monoclonal gammopathy of undetermined significance in a patient with Gaucher's disease," Archives of Pathology and Laboratory Medicine, vol. 121, no. 10, pp. 11081111, 1997.

[25] H. Harder, J. Eucker, C. Zang et al., "Coincidence of Gaucher's disease due to a 1226G/1448C mutation and of an immunoglobulin G lambda multiple myeloma with BenceJones proteinuria," Annals of Hematology, vol. 79, no. 11, pp. 640-643, 2000. 
[26] F. Mateja, J. Malý, M. Tichý, and F. Langr, "Uncommon combination of multiple myeloma in three patients," Vnitrni lekarstvi, vol. 46, no. 7, pp. 413-417, 2000.

[27] B. E. Rosenbloom, N. J. Weinreb, A. Zimran, K. A. Kacena, J. Charrow, and E. Ward, "Gaucher disease and cancer incidence: a study from the Gaucher Registry," Blood, vol. 105, no. 12, pp. 4569-4572, 2005.

[28] M. De Fost, S. Vom Dahl, G. J. Weverling et al., "Increased incidence of cancer in adult Gaucher disease in Western Europe," Blood Cells, Molecules, and Diseases, vol. 36, no. 1, pp. 53-58, 2006.

[29] T. H. Taddei, K. A. Kacena, M. Yang et al., "The underrecognized progressive nature of N370S Gaucher disease and assessment of cancer risk in 403 patients," American Journal of Hematology, vol. 84, no. 4, pp. 208-214, 2009.

[30] S. M. Lo, P. Stein, S. Mullaly et al., "Expanding spectrum of the association between type 1 Gaucher disease and cancers: a series of patients with up to 3 sequential cancers of multiple types-correlation with genotype and phenotype," American Journal of Hematology, vol. 85, no. 5, pp. 340-345, 2010.

[31] M. Chang Lo, L. T. Yam, A. I. Rubenstone, and S. O. Schwartz, "Gaucher's disease associated with chronic lymphocytic leukaemia, gout and carcinoma," Journal of Pathology, vol. 116, no. 4, pp. 203-207, 1975.

[32] T. Mark, C. Dominguez, and A. M. Rywlin, "Gaucher's disease associated with chronic lymphocytic leukemia," Southern Medical Journal, vol. 75, no. 3, pp. 361-363, 1982.

[33] H. Fox, P. McCarthy, J. Andre-Schwartz, Y. Shoenfeld, and K. B. Miller, "Gaucher's disease and chronic lymphocytic leukemia. Possible pathogenetic link between Gaucher's disease and B-cell proliferations?" Cancer, vol. 54, no. 2, pp. 312314, 1984.

[34] S. Kaufman, V. Rosenfeld, R. Yona, and M. Varon, "Gaucher's disease associated with chronic lymphocytic leukaemia," Clinical and Laboratory Haematology, vol. 8, no. 4, pp. 321-324, 1986.

[35] E. Shinar, Z. L. Gershon, R. Leiserowitz, Y. Matzner, S. Yatziv, and A. Polliack, "Coexistence of Gaucher Disease and Philadelphia positive chronic granulocytic leukemia," American Journal of Hematology, vol. 12, no. 2, pp. 199-202, 1982.

[36] P. E. Petrides, P. LeCoutre, J. Müller-Höcker et al., "Coincidence of Gaucher's disease due to a private mutation and Ph' positive chronic myeloid leukemia," American Journal of Hematology, vol. 59, no. 1, pp. 87-90, 1998.

[37] J. R. Krause, C. Bures, and R. E. Lee, "Acute leukaemia and Gaucher's disease," Scandinavian Journal of Haematology, vol. 23, no. 2, pp. 115-118, 1979.

[38] G. M. Corbett, P. J. Darbyshire, G. T. Besley, and A. C. Parker, "Adult Gaucher disease in association with acute leukaemia," Postgraduate Medical Journal, vol. 63, no. 744, pp. 899-900, 1987.

[39] A. Ranade, S. Selegean, G. Sandhu, V. Ghali, and V. P. Shan, "Acute lymphoblastic leukemia in a patient with type 1 Gaucher disease developing 1 year after discontinuation of enzyme replacement therapy," American Journal of Hematology, vol. 85, no. 11, pp. 908-909, 2010.

[40] J. D. Brody, R. Advani, L. K. Shin, D. B. Bingham, and S. A. Rosenberg, "Splenic diffuse large B-cell lymphoma in a patient with type 1 Gaucher disease: Diagnostic and therapeutic challenges," Annals of Hematology, vol. 85, no. 11, pp. 817-820, 2006.
[41] R. Sanchez, J. Etzell, G. Kim, S. Packman, C. Fairley, and R. Goldsby, "Pediatric malignancies: case 2. Peripheral Tcell lymphoma in an adolescent with unsuspected Gaucher disease," Journal of Clinical Oncology, vol. 23, no. 21, pp. 47924793, 2005.

[42] L. R. Sharer, J. A. Barondess, R. T. Silver, and G. F. Gray, "Association of Hodgkin disease and Gaucher disease," Archives of Pathology and Laboratory Medicine, vol. 98, no. 6, pp. 376-378, 1974.

[43] S. Y. Cho and M. Sastre, "Coexistence of Hodgkin's disease and Gaucher's disease," American Journal of Clinical Pathology, vol. 65, no. 1, pp. 103-108, 1976.

[44] A. H. Bruckstein, A. Karanas, and J. J. Dire, "Gaucher's disease associated with Hodgkin's disease," American Journal of Medicine, vol. 68, no. 4, pp. 610-613, 1980.

[45] J. C. Lyons, B. W. Scheithauer, and W. W. Ginsburg, "Gaucher's disease and glioblastoma multiforme in two siblings. A clinicopathologic study," Journal of Neuropathology and Experimental Neurology, vol. 41, no. 1, pp. 45-53, 1982.

[46] S. H. Tsung and E. Cotes, "Coexistence of bronchogenic carcinoma and Gaucher disease," Archives of Pathology and Laboratory Medicine, vol. 101, no. 1, p. 56, 1977.

[47] J. P. Leone and A. Z. Dudek, "Enzyme replacement therapy for Gaucher's disease in patient treated for non-small cell lung cancer," Anticancer Research, vol. 28, no. 6B, pp. 3937-3939, 2008.

[48] M. Kojiro, M. Kage, H. Abe, M. Imamura, K. Shiraishi, and M. Mizoguchi, "Association of dysgerminoma and Gaucher's disease," Cancer, vol. 51, no. 4, pp. 712-715, 1983.

[49] Z. Erjavec, C. E. Hollak, and E. G. De Vries, "Hepatocellular carcinoma in a patient with Gaucher disease on enzyme supplementation therapy," Annals of Oncology, vol. 10, no. 2, p. 243, 1999.

[50] R. Xu, P. Mistry, G. Mckenna et al., "Hepatocellular carcinoma in type 1 Gaucher disease: a case report with review of the literature," Seminars in Liver Disease, vol. 25, no. 2, pp. 226229, 2005.

[51] M. Wantanabe, M. Yanagisawa, S. Sonobe, J. Matsumoto, and H. Miura, "An adult form of Gaucher's disease with a huge tumour formation of the right tibia," International Orthopaedics, vol. 8, no. 3, pp. 195-202, 1984.

[52] M. R. Pins, H. J. Mankin, R. J. Xavier, D. I. Rosenthal, G. R. Dickersin, and A. E. Rosenberg, "Malignant epithelioid hemangioendothelioma of the tibia associated with a bone infarct in a patient who had Gaucher disease. A case report," Journal of Bone and Joint Surgery, vol. 77, no. 5, pp. 777-781, 1995.

[53] P. Bhm, W. Kunz, H. P. Horny, and H. Einsele, "Adult Gaucher disease in association with primary malignant bone tumors," Cancer, vol. 91, no. 3, pp. 457-462, 2001.

[54] S. Zver, M. Bracko, and D. Andoljsek, "Primary bone angiosarcoma in a patient with Gaucher disease," International Journal of Hematology, vol. 92, no. 2, pp. 374-377, 2010.

[55] R. Costello, T. O'Callaghan, and G. Sébahoun, "Gaucher disease and multiple myeloma," Leukemia and Lymphoma, vol. 47, no. 7, pp. 1365-1368, 2006.

[56] Y. Shoenfeld, L. A. Gallant, M. Shaklai, E. Livni, M. Djaldetti, and J. Pinkhas, "Gaucher's disease: a disease with chronic stimulation of the immune system," Archives of Pathology and Laboratory Medicine, vol. 106, no. 8, pp. 388-391, 1982.

[57] D. A. Hughes, "Enzyme, substrate, and myeloma in Gaucher disease," American Journal of Hematology, vol. 84, no. 4, pp. 199-201, 2009. 
[58] H. Michelakakis, C. Spanou, A. Kondyli et al., "Plasma tumor necrosis factor- $\alpha$ (TNF- $\alpha$ ) levels in the Gaucher disease," Biochimica et Biophysica Acta, vol. 1317, no. 3, pp. 219-222, 1996.

[59] M. J. Allen, B. J. Myer, A. M. Khokher, N. Rushton, and T. M. Cox, "Pro-inflammatory cytokines and the pathogenesis of Gaucher's disease: Increased release of interleukin-6 and interleukin-10," QJM, vol. 90, no. 1, pp. 19-25, 1997.

[60] C. E. Hollak, L. Evers, J. M. Aerts, and M. H. Van Oers, "Elevated levels of M-CSF, ${ }_{s}$ CD14 and IL8 in type 1 Gaucher disease," Blood Cells, Molecules and Diseases, vol. 23, no. 2, pp. 201-212, 1997.

[61] V. Barak, M. Acker, B. Nisman et al., "Cytokines in Gaucher's disease," European Cytokine Network, vol. 10, no. 2, pp. 205210, 1999.

[62] M. de Fost, T. A. Out, F. A. de Wilde et al., "Immunoglobulin and free light chain abnormalities in Gaucher disease type I: data from an adult cohort of 63 patients and review of the literature," Annals of Hematology, vol. 87, no. 6, pp. 439-449, 2008.

[63] P. M. Campeau, M. Rafei, M. N. Boivin, Y. Sun, G. A. Grabowski, and J. Galipeau, "Characterization of Gaucher disease bone marrow mesenchymal stromal cells reveals an altered inflammatory secretome," Blood, vol. 114, no. 15, pp. 3181-3190, 2009.

[64] S. H. Dikman, M. Goldstein, T. Kahn, M. Leon, and N. J. Weinreb, "Amyloidosis: an unusual complication of Gaucher's disease," Archives of Pathology and Laboratory Medicine, vol. 102, no. 9, pp. 460-462, 1978.

[65] S. M. Hanash, D. L. Rucknagel, K. P. Heidelberger, and N. S. Radin, "Primary amyloidosis associated with Gaucher's disease," Annals of Internal Medicine, vol. 89, no. 5 I, pp. 639641, 1978.

[66] A. Kaloterakis, A. Filiotou, J. Koskinas et al., "Systemic A.L. amyloidosis in Gaucher disease: a case report and review of the literature," Journal of Internal Medicine, vol. 246, no. 6, pp. 587-590, 1999.

[67] Y. Burstein, V. Zakuth, G. Rechavi, and Z. Spirer, "Abnormalities of cellular immunity and natural killer cells in Gaucher's disease," Journal of Clinical and Laboratory Immunology, vol. 23, no. 3, pp. 149-151, 1987.

[68] L. A. Boven, M. Van Meurs, R. G. Boot et al., "Gaucher cells demonstrate a distinct macrophage phenotype and resemble alternatively activated macrophages," American Journal of Clinical Pathology, vol. 122, no. 3, pp. 359-369, 2004.

[69] A. Balreira, L. Lacerda, C. S. Miranda, and F. A. Arosa, "Evidence for a link between sphingolipid metabolism and expression of CD1d and MHC-class II: monocytes from Gaucher disease patients as a model," British Journal of Haematology, vol. 12, no. 5, pp. 667-676, 2005.

[70] P. K. Mistry, J. Liu, M. Yang et al., "Glucocerebrosidase gene-deficient mouse recapitulates Gaucher disease displaying cellular and molecular dysregulation beyond the macrophage," Proceedings of the National Academy of Sciences of the United States of America, vol. 107, pp. 19473-19478, 2010.

[71] I. Ron and M. Horowitz, "ER retention and degradation as the molecular basis underlying Gaucher disease heterogeneity," Human Molecular Genetics, vol. 14, no. 16, pp. 2387-2398, 2005.

[72] J. DePaolo, O. Goker-Alpan, T. Samaddar, G. Lopez, and E. Sidransky, "The association between mutations in the lysosomal protein glucocerebrosidase and parkinsonism," Movement Disorders, vol. 24, no. 11, pp. 1571-1578, 2009.
[73] P. K. Mistry, N. J. Weinreb, R. O. Brady, and G. A. Grabowski, "Gaucher disease: resetting the clinical and scientific agenda," American Journal of Hematology, vol. 84, no. 4, pp. 205-207, 2009.

[74] A. Zimran, I. Liphshitz, M. Barchana, A. Abrahamov, and D. Elstein, "Incidence of malignancies among patients with type I Gaucher disease from a single referral clinic," Blood Cells, Molecules, and Diseases, vol. 34, no. 3, pp. 197-200, 2005.

[75] O. Landgren, I. Turesson, G. Gridley, and N. E. Caporaso, "Risk of malignant disease among 1525 adult male US veterans with Gaucher disease," Archives of Internal Medicine, vol. 167, no. 11, pp. 1189-1194, 2007.

[76] N. J. Weinreb, H. C. Andersson, M. Banikazemi et al., "Prevalence of type 1 Gaucher disease in the United States," Archives of Internal Medicine, vol. 168, no. 3, pp. 326-327, 2008.

[77] B. E. Rosenbloom, P. Becker, and N. Weinreb, "Multiple myeloma and Gaucher genes," Genetics in Medicine, vol. 11, no. 2, p. 134, 2009.

[78] A. Zimran, Y. Ilan, and D. Elstein, "Enzyme replacement therapy for mild patients with Gaucher disease," American Journal of Hematology, vol. 84, no. 4, pp. 202-204, 2009.

[79] J. Mitsui, I. Mizuta, A. Toyoda et al., "Mutations for Gaucher disease confer high susceptibility to Parkinson disease," Archives of Neurology, vol. 66, no. 5, pp. 571-576, 2009.

[80] I. Ron, D. Rapaport, and M. Horowitz, "Interaction between parkin and mutant glucocerebrosidase variants: A possible link between Parkinson disease and Gaucher disease," Human Molecular Genetics, vol. 19, no. 19, pp. 3771-3781, 2010.

[81] Y. H. Xu, B. Quinn, D. Witte, and G. A. Grabowski, "Viable mouse models of acid $\beta$-glucosidase deficiency: the defect in Gaucher disease," American Journal of Pathology, vol. 163, no. 5, pp. 2093-2101, 2003.

[82] G. B. Sinclair, G. Jevon, K. E. Colobong, D. R. Randall, F. Y. M. Choy, and L. A. Clarke, "Generation of a conditional knockout of murine glucocerebrosidase: utility for the study of Gaucher disease," Molecular Genetics and Metabolism, vol. 90, no. 2, pp. 148-156, 2007.

[83] I. H. Park, N. Arora, H. Huo et al., "Disease-specific induced pluripotent stem cells," Cell, vol. 134, no. 5, pp. 877-886, 2008.

[84] Y. Sun, B. Liou, H. Ran et al., "Neuronopathic Gaucher disease in the mouse: viable combined selective saposin $\mathrm{C}$ deficiency and mutant glucocerebrosidase (V394L) mice with glucosylsphingosine and glucosylceramide accumulation and progressive neurological deficits," Human Molecular Genetics, vol. 19, no. 6, pp. 1088-1097, 2010.

[85] Y. H. Xu, L. Jia, B. Quinn et al., "Global gene expression profile progression in Gaucher disease mouse models," BMC Genomics, vol. 1, no. 1, article 20, 2011.

[86] D. Hughes, M. D. Cappellini, M. Berger et al., "Recommendations for the management of the haematological and oncohaematological aspects of Gaucher disease," British Journal of Haematology, vol. 138, no. 6, pp. 676-686, 2007. 

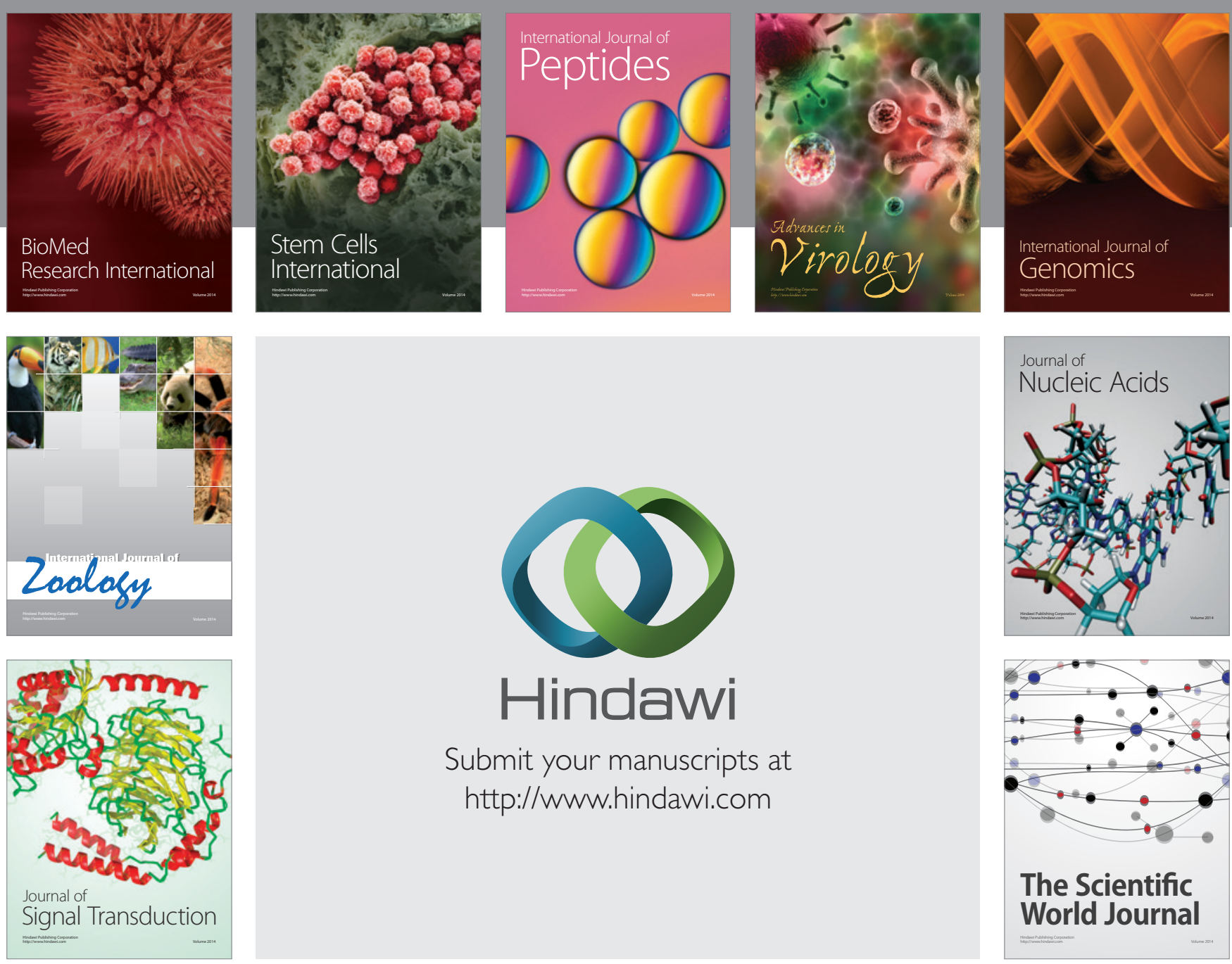

Submit your manuscripts at

http://www.hindawi.com
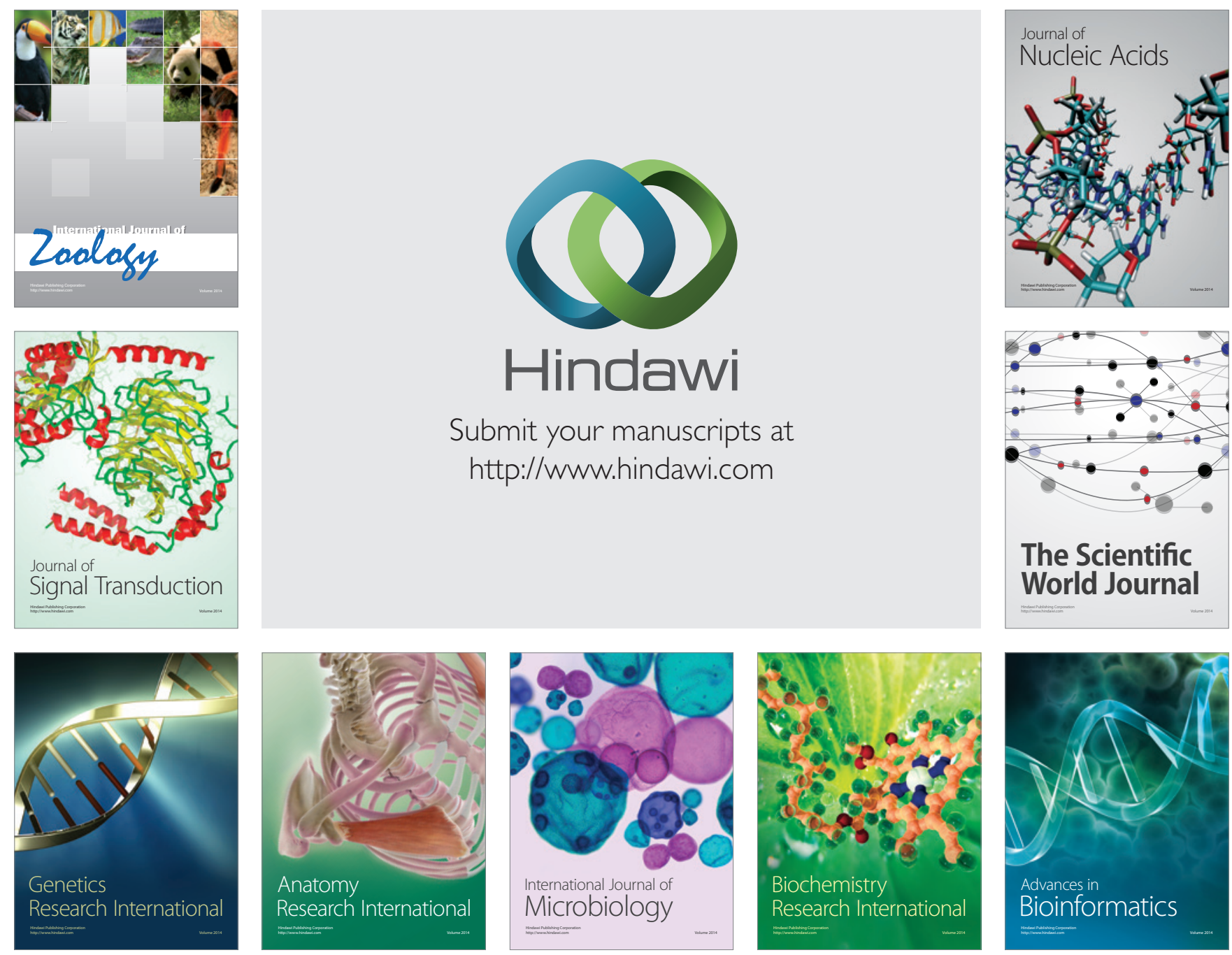

The Scientific World Journal
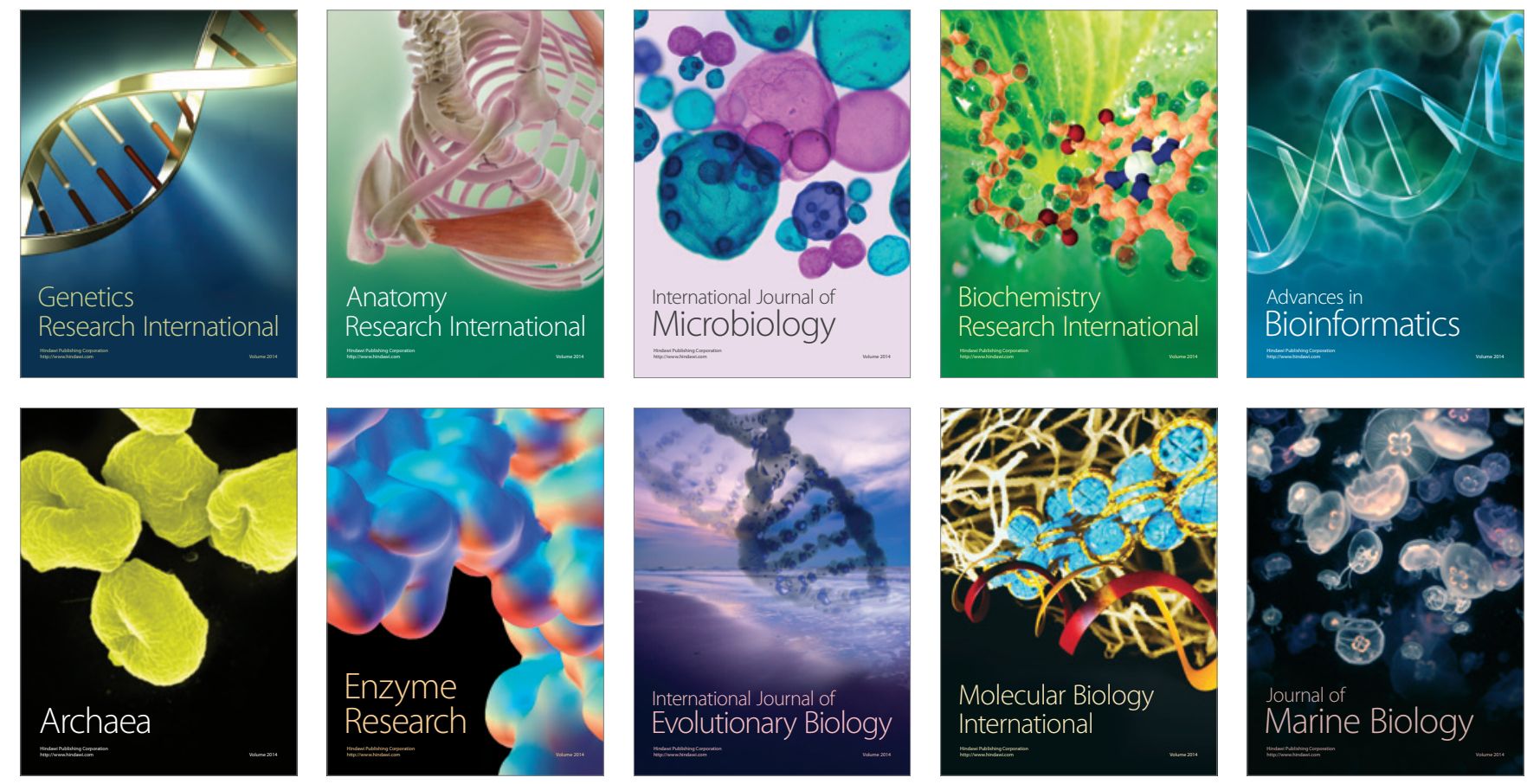